\title{
A Review: The Bioactivities and Pharmacological Applications of Polygonatum sibiricum polysaccharides
}

\author{
Xiaowei Cui ${ }^{1}{ }^{10}$, Shiyuan Wang ${ }^{2}$, Hui Cao ${ }^{1}$, Hong Guo ${ }^{1}$, Yujuan Li ${ }^{1}$, Fangxue Xu ${ }^{1}$, \\ Mengmeng Zheng ${ }^{1}$, Xiaozhi $\mathrm{Xi}^{1}$ and Chunchao Han ${ }^{1, *}$ \\ 1 School of Pharmacy, Shandong University of Traditional Chinese Medicine, Jinan 250355, China; \\ 13553159162@163.com (X.C.); 13553158985@163.com (H.C.); m13589080261@163.com (H.G.); \\ yjli_0531@163.com (Y.L.); xfx18364164925@163.com (F.X.); 18364166659@163.com (M.Z.); \\ 18364167331@163.com (X.X.) \\ 2 School of Traditional Chinese Medicine, Shandong University of Traditional Chinese Medicine, \\ Jinan 250355, China; wsy0534@126.com \\ * Correspondence: cch@sdutcm.edu.cn; Tel./Fax: +86-531-8261-3129
}

Received: 14 April 2018; Accepted: 8 May 2018; Published: 14 May 2018

\begin{abstract}
Traditional Chinese Medicine (TCM) has been widely used in China and is regarded as the most important therapeutic. Polygonatum sibiricum (PS), a natural plant used in traditional Chinese medicine, has various functions associated with a number of its components. There are many compositions in PS including polysaccharides, steroids, anthraquinone, alkaloids, cardiac glycosides, lignin, vitamins, various acids, and so on. Of these, polysaccharides play a significant role in PS-based therapeutics. This article summarizes Polygonatum sibiricum polysaccharides (PSP) have many pharmacological applications and biological activities, such as their antioxidant activity, anti-aging activity, an anti-fatigue effect, immunity enhancement effect, antibacterial effect, anti-inflammatory effect, hypolipidemic and antiatherosclerotic effects, anti-osteoporosis effect, liver protection, treatment of diabetes mellitus (DM), anti-cancer effect, and may help prevent Alzheimer's disease, and so on. This review summarized the extraction method, purification method, compositions, pharmacological applications, biological activities, biosynthesis, and prospects of PSP, providing a basis for further study of PS and PSP.
\end{abstract}

Keywords: Polygonatum sibiricum polysaccharides (PSP); compositions; pharmacological applications; biological activity; biosythesis; prospects

\section{Introduction}

Polygonatum sibiricum (PS) is a dry rhizome of Polygonatum kingianum Coll. Et Hemsl., Polygonatum sibiricum Red., or Polygonatum cytomema Hua. which was introduced in the 2015 edition of pharmacopoeia. It is from the liliaceae plant which is distributed throughout the temperate Northern Hemisphere such as China, Japan, Korea, India, Russia, Europe, and North America [1-3]. Of these, China especially has abundant resources of PS. PS has a sweet fragrance and taste and is well-known as a traditional medicinal herb and functional food in China $[4,5]$ as well as a health-improving substance [6]. PS has been reported to have many pharmacological applications and biological activities, such as antioxidant activity and anti-aging activity. It also has anti-osteoporosis, neuroprotective, immunity enhancement, anti-diabetic, anti-fatigue, and anti-cancer, effects [1,7-9]. PS has been used to treat fatigue, weakness, diabetes mellitus (DM), cough, indigestion, inappetence, sexual dysfunction, backache, and keen pain. Many publications have reviewed the chemical constituents, biological activities, and food use of PS $[1,10]$. The abundant biological activities have been attributed to the presence of multiple components, such as alkaloids, flavones, steroid saponins, lignins, amino 
acids, and polysaccharides (PSP) $[5,8,11,12]$. PSP are believed to be one of the most important active compounds of PS [13].

Water-soluble extractions of PSP, known for their low toxicity, are suitable for long-term administration for various activities and effects $[1,5]$. PSP were found to be the major contributors to the sweet taste of PS which makes the food more readily accepted [14]. At present, PSP are widely used in TCM therapy for cardiovascular diseases and other diseases [15-20]. In conclusions, PSP play an important role in PS, which is commonly used in people's lives.

\section{Chemical Constitutions of PSP}

PSP, when extracted with hot water, were mainly composed of fructose, [21]. Some articles, through research of PSP chemical composition and weight determination, structure analysis, and functional activity testing, confirmed that PSP were composed of monosaccharides, which mainly include mannose (Man), galactose (Gal), glucose (Glc), fructose (Fru), rhammnose (Rha), arabinose (Ara), and galacturonic acid (GalA), as well as small amounts of xylose (Xyl) and glucuronic acid (GlcA). PSP were found that consisted of a branched homogalactan and branched galactomannans [1,3].

A study confirmed that crude PSP consisted of carbohydrates $(85.1-88.3 \%)$ with proteins (4.51-11.9\%) and uronic acid (1.79-7.47\%) and included different percentage compositions of Man (62.3-76.3\%), Glu (15.2-20.3\%), Gal (4.35-15.3\%), and Ara (4.00-7.65\%) [4,5]. Another article indicated that Gal and Rha were the main components of PSP with little amounts of Man, Glu, and Xyl. It was confirmed that the ratio of Gal, Rha, Man, Glu, and Xyl were at $63.50 \%, 25.14 \%, 8.04 \%, 1.75 \%$, and $15 \%$, respectively [7].

\section{Extraction and Purification Methods}

The traditional extraction method of PSP is water extraction. PS was pretreated and extracted by using the hot water extraction method to get more PSP. Crude PSP were obtained, then ethanol precipitation was used to remove inactive substances and proteins [7]. The influencing factors in the process were extraction temperature, extraction frequency, extraction time, and solvent use. Chen Gang et al. [22] extracted PSP by a hot water extraction method optimized with the response surface method to get the optimal extraction condition. The result demonstrated that the optimal extraction conditions are as follows; solid to liquid ratio was $1: 21.5$, temperature was $73.5^{\circ} \mathrm{C}$, extraction time was $2.5 \mathrm{~h}$. The extraction rate of PSP can reach $12.25 \%$ under these extraction conditions [23].

Dilute lye can help remove the chemical effects of plant cell wall molecules, then destroy the cell wall so that the active ingredient dissolves out of the cell, ultimately giving a higher yield of PSP [24]. The study demonstrated that the optimal conditions are as follows, crushing granularity was 60 mesh, alkali liquor was 3\% $\mathrm{NaOH}$ solution, and the solid to liquid ratio was 1:15. The reaction it is then left overnight and then the final PSP extraction rate can reach $11.89 \%$. However, the dilute alkali causes breakage of the glycosidic bonds of PSP. Therefore, the PH of the extracted liquid must be rapidly adjusted to avoid hydrolysis of PSP [23-25].

There are several other extraction methods for PSP, such as enzymatic hydrolysis extraction, ultrasonic crushing and extraction, microwave-assisted extraction, and so on [24]. Table 1 lists these methods.

Table 1. Polygonatum sibiricum polysaccharide (PSP) extraction methods.

\begin{tabular}{ccccc}
\hline Extraction Methods & Solid-liquid Ratio & Temperature $\left({ }^{\circ} \mathbf{C}\right)$ & Time (h) & Extraction Rate (\%) \\
\hline Water extraction method & $1: 21.5$ & 73.5 & 2.5 & 12.25 \\
Dilute lye extraction method & $1: 15$ & Room temperature & 12 & 11.89 \\
Other extraction methods & $\begin{array}{c}\text { Enzymatic hydrolysis extraction method, Ultrasonic crushing and extraction method, } \\
\text { Microwave-assisted extraction }\end{array}$ & \\
\hline
\end{tabular}




\section{Biological Activities}

\subsection{Antioxidant Activity and Anti-Aging Activity}

PSP significantly reduces the malondialchehyche (MDA) content of skeletal muscle and serum, decreases free radical activity, and enhances the activity of superoxide dismutase (SOD) and glutathione peroxidase (GSH-Px) $[19,25,26]$. The article confirmed that PSP could protect human umbilical vein endothelial cells from damage induced by lipopolysaccharide [27]. At the same time, PSP can not only increase $\mathrm{Na}+\mathrm{K}+-\mathrm{ATP}$ and $\mathrm{Ca} 2+-\mathrm{ATP}$ activity in mouse brain cells to prevent aging via Ca2+ overload, but it can also reduce the level of lipid peroxide (LPO), lipofuscin (LF), and B-type monoamine oxidase (MAO-B), thereby enhancing the body's anti-damage and anti-aging effects [26,28]. Lu et al. demonstrated that there was a high correlation between aging and mitochondrial DNA damage and repaire genes during the aging process. PSP could confer an anti-aging effect through improving the energy metabolism of liver mitochondria, reducing the expression of DNA polymerase $\gamma \mathrm{mRNA}$ and enhancing the activities of respiratory chain enzyme complexes [26]. Furthermore, PSP could enhance the antioxidant capacity of natural menopausal rats and improve their blood lipid metabolism to delay senescence [29]. Therefore, it plays an important role as an antioxidant and can delay senescence.

\subsection{Anti-Fatigue Function}

Recently, PSP has been studied as a new, natural anti-fatigue substance [30-32]. A previous study confirmed that PSP may have ergogenic and anti-fatigue functions [33]. Treatment with PSP decreases blood lactate and serum urea nitrogen and increases liver and muscle glycogen, all of which result in a reduction of fatigue [26,34]. Treatment with PSP could significantly prolong swimming time in mice. The results showed that PSP could improve the exercise endurance and enhance the fatigue resistance effect of mice $[19,20]$.

\subsection{Immunity Enhancement Effect}

Some articles have shown that the immunologic functioning of mice could be increased by treatment with PSP [7,19,21,35-38]. For example, a PSP treatment group exhibited stimulation of natural red phagocytosis of RAW264.7 macrophages compared with the cyclophosphamide (Cy) treatment group. Furthermore, significantly accelerated recovery of spleen and thymus indices were recorded in mice [19]. PSP could enhance T and B cell proliferation responses as well as peritoneal macrophage phagocytosis. It could also restore the levels of interleukin-2 (IL-2), tumor necrosis factor (TNF- $\alpha$ ), interleukin (IL-8), and IL-10 in serum which was treated with Cy in a dose-dependent manner. In conclusion, PSP could be used as an immunostimulant for protection against immunosuppression in Cy-treated mice [7].

The most recognized changes in the immune system were involution of the thymus and the diminished output of $\mathrm{T}$ lymphocytes [35]. The article found that the absolute number of total $\mathrm{T}$ cells (CD3+), involving both CD4+ and CD8+ subsets and the immune responses mediated by them, displayed an age-dependent decline [36]. Treatment with PSP significantly reversed the decline in the thymus and spleen weights, compared to the control group in Cy-induced immunosuppressed mice $[1,37]$. PSP can also promote the formation of hemolysin (an index of specific humoral immune function) and improve the phagocytic activity of peritoneal macrophages in immunosuppressed mice $[1,38]$.

\subsection{Antibacterial Effect and Anti-Inflammatory Effect}

An experiment using the filter paper and cup method showed that PSP had antibacterial effects against Staphylococccus aureus, White Staphylococcus aureus (White S. aureus), Escherichia coil, Bacillus subtilis, Salmonella typhi, Paratyphoid bacillus, Micrococcus luteus [39], Streptomyces microflavus, and Saccharomyces cerevisiae [40]. Another experiment indicated that the minimal inhibition concentration (MIC) of PSP was $0.02 \mathrm{~g} / \mathrm{mL}$ for E. coil and $0.01 \mathrm{~g} / \mathrm{mL}$ for S. aureus and M. luteus. 
When PSP was extracted by the microwave-assisted method, the extraction rate of PSP could be as high as $10.57 \%$ [40]. Another experiment found that PSP could inhibit E. coil, B. subtilis, and S. aureus, with respective MICs of $1.23 \mathrm{mg} / \mathrm{mL}, 0.98 \mathrm{mg} / \mathrm{mL}$, and $1.31 \mathrm{mg} / \mathrm{mL}$ [41]. From previous studies, PSP could also control ear swelling caused by xylene. The mechanism of these effects may involve reducing the level of inflammatory mediators in the serum, but the specific mechanisms still need further study [19]. Figure 1 shows all the known biological activity mechanisms of PSP.

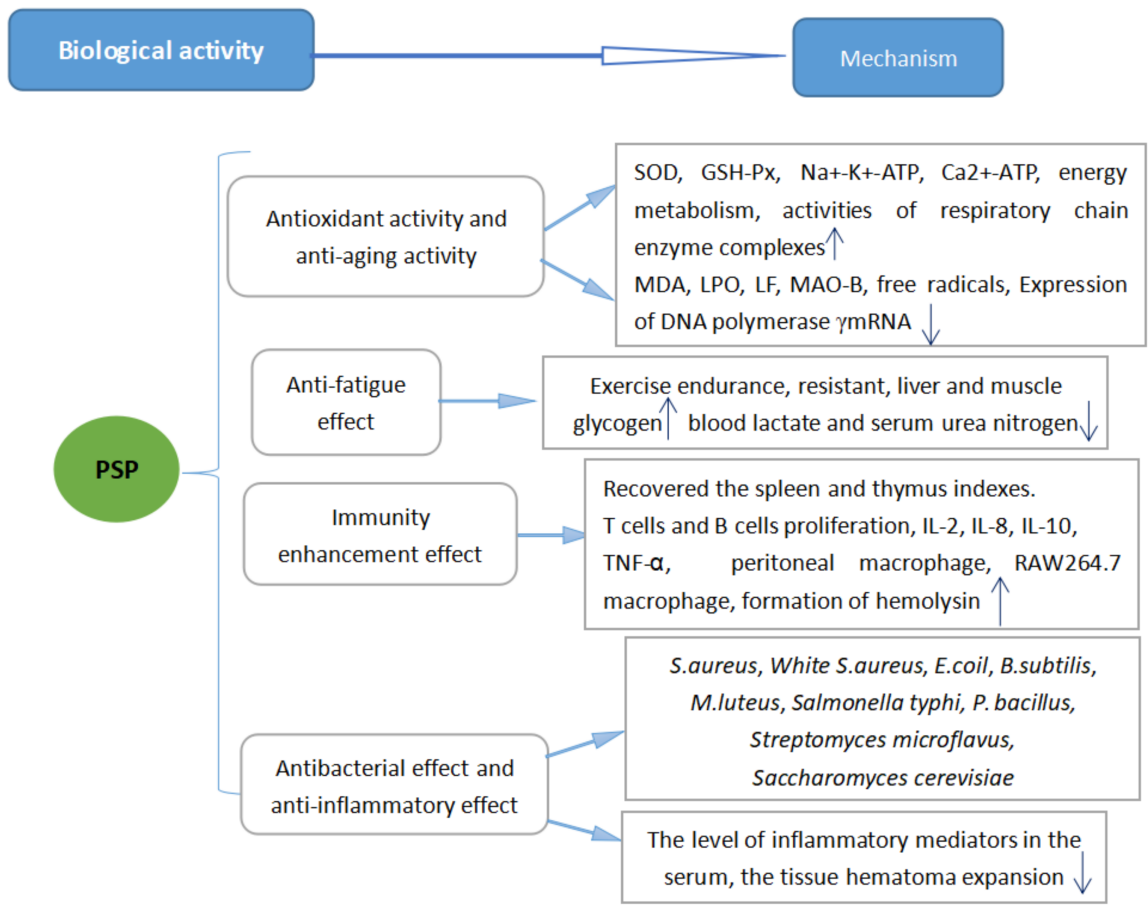

Figure 1. The biological activities of PSP and their mechanisms.

\section{Pharmacological Applications}

\subsection{Prevention of Alzheimer's Disease (AD)}

Neurodegeneration is a pathological condition of brain cells [42,43]. A study supposed that amyloid $\beta$-peptide $(\mathrm{A} \beta)$-induced oxidative stress led to neurodegeneration in the AD brain [44]. An in vitro study showed that pretreatment with PSP could remarkably reduce the apoptotic rate and elevate the $\mathrm{Bax} / \mathrm{Bcl}-2$ ratio in rat PC12 cells and inhibit mitochondrial dysfunction and cytochrome release into the cytosol. Pretreatment with a P13K inhibitor could abolish the protective effects of PSP. In addition, A 325 -35-induced Caspase-3 activation was inhibited and the protein levels of phosphorylated Akt (p-Akt) were enhanced in PC12 cells upon treatment with PSP. So, the protective effect of PSP against A $\beta 25$-35-induced apoptosis in PC12 cells could be associated with the enhancement of P13K/Akt signaling [6]. Therefore, we unambiguously suggest that PSP can attenuate $\mathrm{A} \beta$-induced neurotoxicity in PC12 cells. As we all know, $\mathrm{A} \beta$-induced neurotoxicity is a major cause of AD [6]. Others have reported that PSP might have a potential therapeutic effect against AD [45]. According to these studies, PSP could be used to prevent and treat Alzheimer's disease.

\subsection{Treatment of Diabetes Mellitus (DM)}

According to former studies, Alloxan (ALX) and Streptozocin (STZ) could induce DM [26]. Another study investigated the mechanisms of how PSP treatment of DM [26]. Firstly, PSP decreased the blood glucose level and increased the thymus index, spleen index, and liver index in ALX-induced diabetic mice. At the same time, PSP could decrease the content of malondialdehyde (MDA), 
enhance the total superoxide dismutase (T-SOD) and glutathione peroxidase (GSH-Px) in blood serum, and enhance liver tissue of ALX-induced diabetic mice. Secondly, PSP could significantly affect the levels of fasting blood glucose (FGB), glycosylated serum protein (GSP), total cholesterol (TC), and triglyceride (TG) [36,46], and the amount of water drinking, food intake, and urinary volume in the PSP-treated groups were lower than the control group of STZ-induced diabetic mice. PSP decreased the rate of apoptotic cells, the levels of Caspase- 3 and NO in blood serum, and iNOS mRNA expression in STZ-induced diabetic mice [26,47]. They found that the mechanism of the protective effect of PSP on ALX-induced diabetic mice might be related to its antioxidant activity. On the other hand, PSP decreased blood glucose and had some protective activity in STZ-induced diabetic rats. The mechanism of this may be related to inhibition of islet cell apoptosis, Caspase- 3 reduction, and suppression of iNOS mRNA activity [26,48,49]. As PSP could decrease the TG and TC of hyperlipidemic animals, the mechanism may be related to its anti-oxidant effect, immune regulation, or inhibition of inflammatory factors [26].

One of the most common microvascular complications in DM is diabetic retinopathy (DR). A study confirmed that treatment with PSP not only could slow the progression of DR, but could also affect cataract formation through alleviating hyperglycemia and reducing oxidative stress in diabetic mice which induced by STZ [50]. Some previous studies found that compared to the normal rats, the structure of the gut microbiota was significantly changed in diabetic rats treated with PSP. Oral administration with PSP could prevent type II diabetes by its regulatory role on the gut microbiota [51]. Also, PSP-lowered blood sugar and lipids and alleviated fatty liver degeneration in type II diabetes may be associated with the lower expression of SREBP-1c and SCD-1 proteins [52]. PSP could improve myocardial dysfunction in diabetic rates which may be related to its promotion of the expression of bone morphogenetic protein-7 (BMP-7) in cardiac tissue that affected the transforming growth factor- $\beta 1$ (TGF- $\beta 1$ )/Smads signaling pathway [53]. Another study demonstrated that PSP could produce protective effects on myocardial inflammation damage with type I diabetes through reducing blood sugar and lipids and inhabiting inflammatory reactions [54]. It could be used to protect the kidney of diabetic rats by reducing sugar and inhibiting fibrosis [55].

The process of PSP protection against DM is presented in Figure 2.

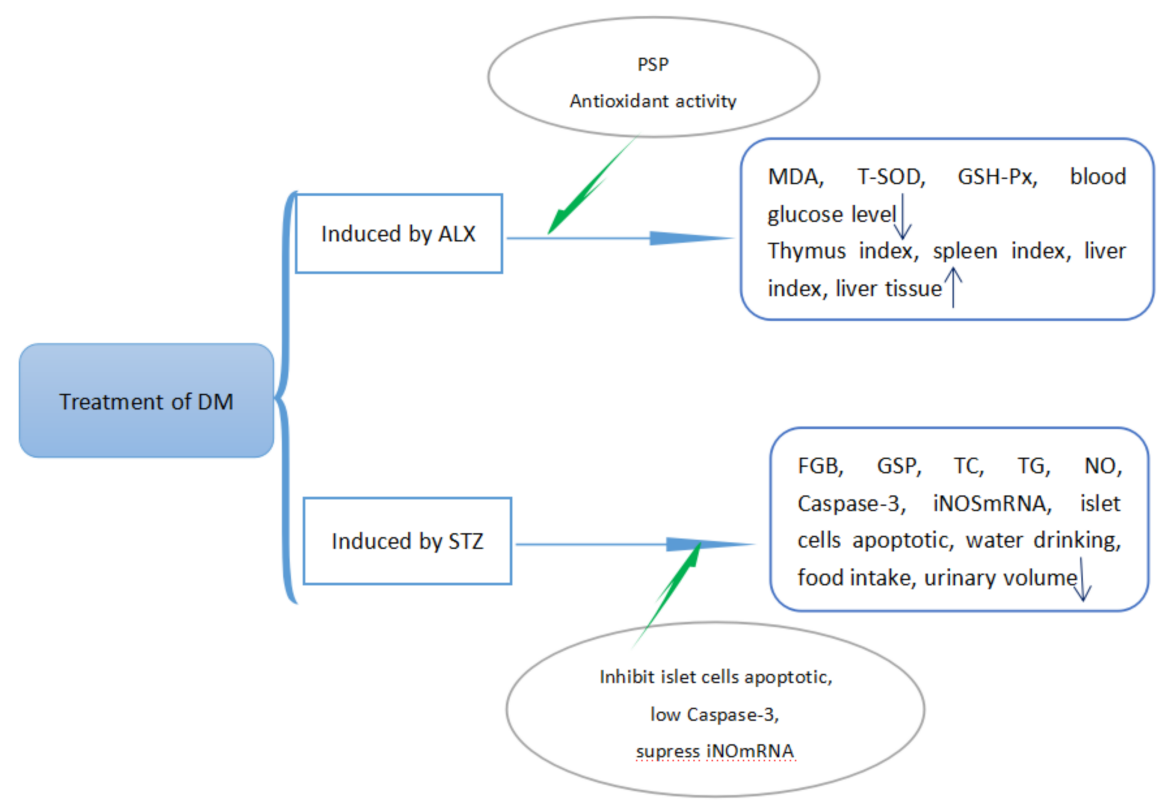

Figure 2. The mechanism of treatment of DM. 


\subsection{Hypolipidemic and Anti-Atherosclerotic Effects}

Some studies confirmed that the hypolipidemic activity of PSP was mainly due to modulation of TC, low-density lipoprotein (LDL-C), and lipoprotein (Lp (a)) in an atherosclerosis model. [16] PSP significantly reduced the intimal foam cells number compared to the control group. According to a study in endothelial cells (ECs), PSP not only affected EC proliferation, but also protected ECs from injury and apoptosis induced by $\mathrm{H}_{2} \mathrm{O}_{2}$ and lipopolysaccharide (LPS). In conclusion, the anti-atherosclerotic effect of PSP may be associated with its hypolipidemic activity, improving aortic morphology function, and reducing foam cells number [16].

Some articles showed that PSP had potential as a pharmaceutical or dietary adjuvant to treat hyperlipidemia and atherosclerosis $[13,15]$. They demonstrated that PSP caused significant improvements in serum lipid profile, apolipoproteins, and endothelial dysfunction parameters. The result showed that PSP had a protective effect against hyperlipidemia-induced atherosclerosis in hamsters [13].

\subsection{Anti-Osteoporosis Effect}

PSP has shown anti-osteoporosis effects and reverses bone loss in vivo [3,56]. The study confirmed that treatment with PSP could inhibit the receptor activation of nuclear factor-KB ligand (RANKL)-induced osteoclastogenesis and exert prophylatic protection against LPS-induced osteolysis in vivo. They found that PSP prevented osteoporosis through the Wnt/ $\beta$-catenin pathway without affecting the bone morphogenetic protein (BMP) signaling pathway. PSP enhanced the osteogenic differentiation of bone marrow mesenchymal stem cells (BMSCs) by increasing the activity of alkaline phosphatase (ALP) and the expression of osteoblastic differentiation makers, such as runt-related transcription factor (RUNX2), bone gla protein (BGP) and the characteristic proteins of osteoblasts and the major sign of the start of mineralization $(\mathrm{OCN})$ [5,57-59]. Another study indicated that PSP promoted osteoblastic differentiation and mineralization via the signal-regulated kinase (ERK)/glycogen synthase $3 \beta$ (GSK-3 $\beta$ )/ $\beta$-catenin signaling pathways [10]. Another experiment demonstrated that PSP could inhibit bone loss in ovariectomize rats and prevent osteoporosis by increasing BMP and basic fibroblast growth factor (bFGF) [60]. From all of these, we draw the conclusion that PSP could be used to treat osteoporosis.

\subsection{Liver Protection}

Jiang et al. showed that administration of PSP could increase rats' final body weight, liver antioxidant enzyme activities (SOD, catalase (CAT), GSH-Px, and glutathione reductase (GR)), decrease serum aspartate aminotransferase (AST), alanine aminotransferase (ALT), alkaline phosphatase (ALP) activities, and liver MDA level which were induced by $\mathrm{CCL}_{4}$ treatment. It was recorded that PSP could decrease the toxicity of $\mathrm{CCL}_{4}$ in mice.

\subsection{Anti-Cancer Effect}

PSP could not only could significantly inhibit the growth of H22-transplantation tumor, stop the cells in the G0/G1 stage, and increase expression of caspases 3, 8, and 9, but could also inhibit human breast cancer cells (MCF-27) and Herps and Eac tumor masses [26,61]. An experiment found that PSP could hold human esophageal cancer ECA-109 cells, human gastric cancer HGC-27 cells, and human colorectal cancer HCT-8 cells in the S stage, promoting their apoptosis [3]. Some studies showed that PSP could inhibit S180 ascites tumor [23,26,62]. An article indicated that PSP could inhibit Hela cells, human breast cancer MDA-MB- 435 cells, human leukemia HL-60 cells, and human lung cancer H14 cells [63]. According to former studies, the effect of PSP on cancer cells might be related to the inhibition of cancer-associated fibroblasts (CAFs). Han et al. found that PSP could inhibit the growth of prostate-CAFs without inhibiting the growth of normal fibroblasts. The important discovery 
was that PSP stimulated autophagy of prostate-CAFs and inhibited prostate-CAF growth, indicating a novel anti-cancer strategy involving the inhibition of the growth of prostate-CAFs [60].

Some articles indicated that the spleen index and thymus index increased in rats after treatment with PSP, so the anti-tumor effect may be associated with immunologic function $[23-26,39,62,63]$.

All of the pharmacological applications of PSP are shown in Figure 3.

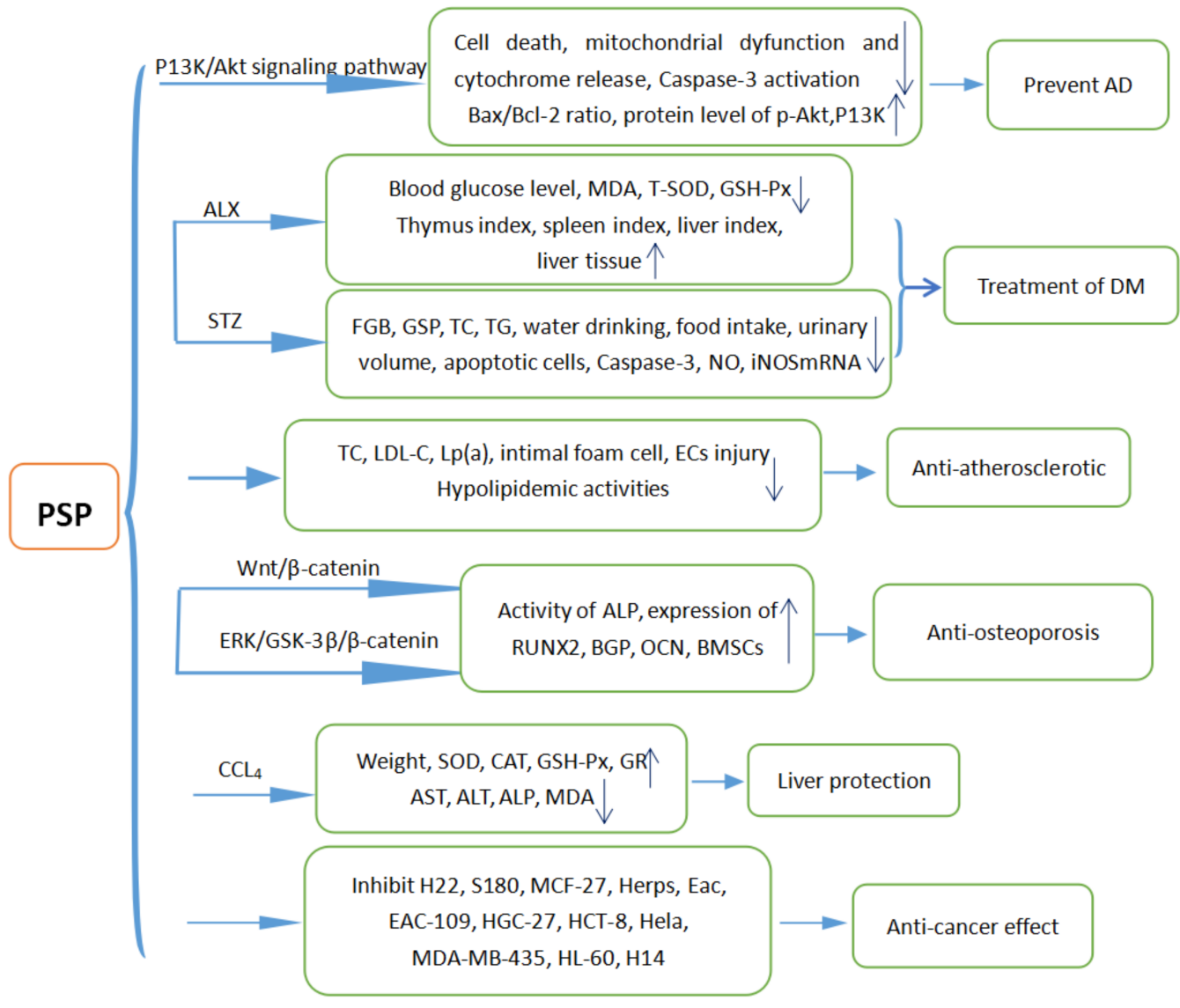

Figure 3. The pharmacological applications of PSP.

\section{Biosynthesis}

Based on some studies [64-72], PSP biosynthesis can be divided into three main stages. Firstly, sucrose is converted to Glc-1P and Fru-6P. During these processes, many enzymes play important roles. $\beta$-fructofuranosidase (encoded by sacA) [66] converts sucrose to Glc-6P and Fructose, phosphoglucomutase (encoded by pgm) isomerizes Glc-6P to Glc-1P [67], and hexokinase (encoded by HK) [68] and fructokinase (encoded by scrK) [69] also take part in the biosynthesis of Fru-6P. Secondly, uridine diphosphate glucose (UDP-Glc) is derived from Glc-1P [70] and Fru-6P is indirectly converted to GDP-Man [71]. UDP-Glc is the key precursor. Based on UDP-Glc and guanosine diphosphomannose (GDP-Man), other nucleotide-diphospho-sugars (NDP-sugars) are further converted through the action of NDP-sugar interconversion enzymes (NSEs) [72], such as UDP-glucose 4-epimerase (GALE), UDP-D-galactose dehydrogenase (UGD), UDP-glucuronate 4-epimerase (UGE), UDP-glucose 6-dehydrogenase (UGDH), UDP-arabinose 4-epimerase (UXE), UDP-glucose 4,6-dehydratase (RHM), 3,5-epimerase-4-redutase (UER1), and GDP-mannose 4,6-dehydratase (GMDS). Finally, various NDP-sugars are obtained by growing polysaccharide chains by the action of glycosyltransferase (GTs) [14]. Figure 4 shows the biosynthesis process of PSP. 


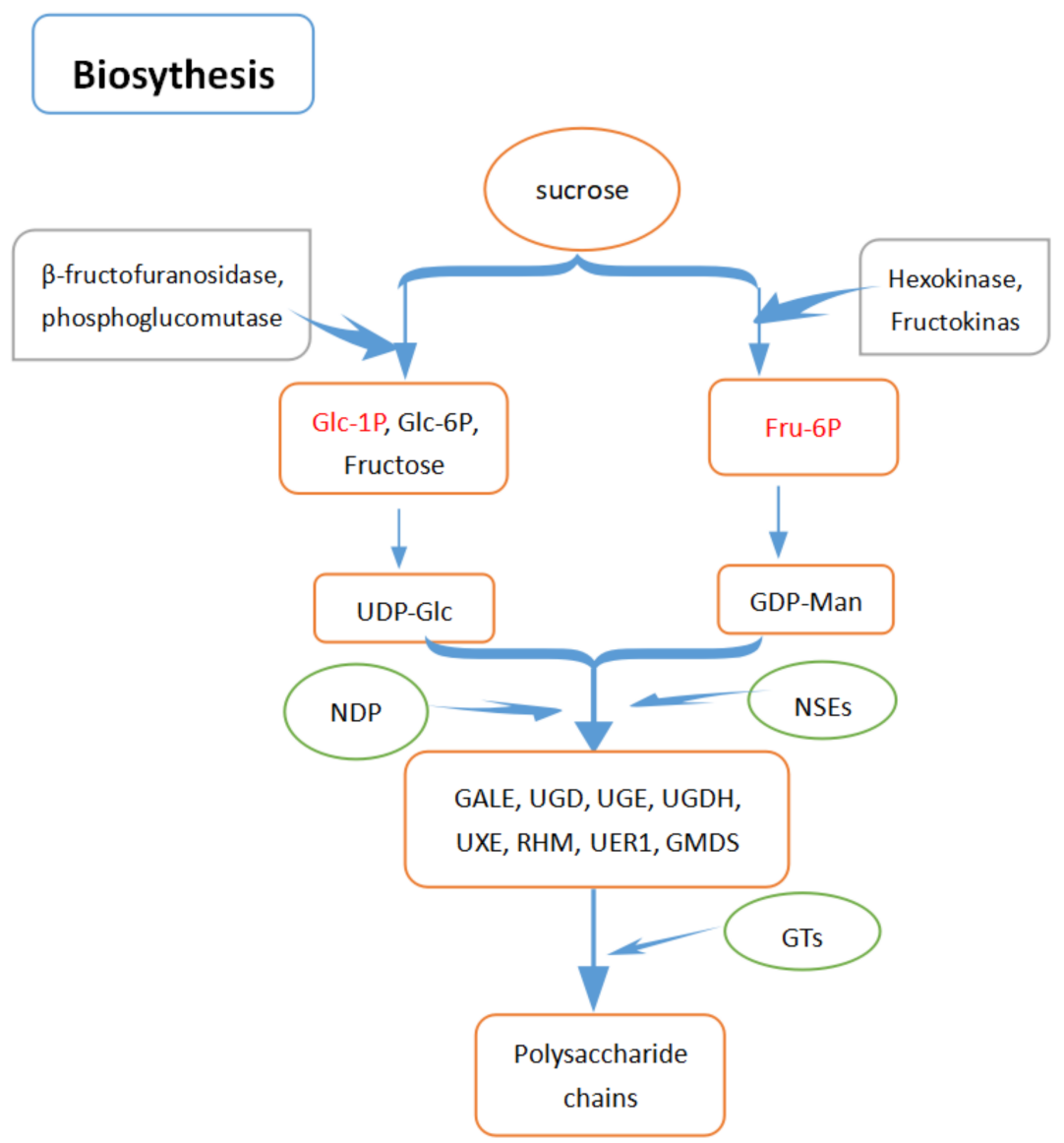

Figure 4. The biosynthesis of PSP.

\section{Future Prospects}

With the growth of science and technology growth of the modern society, the pollution of the environment, and the intensification of competition, there is increasing pressure and worry. This results in an increasing level of sickness, particularly manifesting as immune decline, premature aging, cancer onset, and other sub-health phenomena. Thus, health and longevity become people's goals, to maintain health and slow down the function of aging [26]. PSP, as a kind of medicine and food, is praised by the general consumer due to its various activities. In addition, China's resources of PS are abundant, providing strong potential for its development and utilization. The study of PSP pharmacodynamics, chemical composition, and molecular structure are still incomplete. Therefore, more studies are needed in order to discover its chemical composition and the mechanisms of its biological functions in vivo and in vitro for its safe application in human health care [3].

Thus, more chemical constituents will be isolated from PS and their pharmaceutical activities will become better understood with the development of science and technology.

\section{Conclusions}

PS, as a TCM with broad prospects for development, has a long medical history in China. Study of PS is mainly concentrated on its steroid saponins and polysaccharides. PSP as the most important component of PS and has become more and more popular due to its various pharmacological applications and biological activities. It can be used to treat many clinical diseases, such as Alzheimer's disease, hypolipidemia, atherosclerosis, osteoporosis, liver disease, diabetes mellitus (DM), and cancer. These pharmacological applications and bioactivities are associated with its structure. In terms of pharmacological activity, there is a lack of studies on monomeric compounds and their mechanisms of 
action. Therefore, we should pay attention to the extraction and site of activity to elucidate the basis of its pharmacophore, in order to provide the necessary scientific basis for its further development and utilization.

Acknowledgments: This work was supported by Project of Shandong Province Key Research and Development Program (2017YYSP030).

Conflicts of Interest: The authors declare no conflict of interest.

\section{References}

1. Zhao, P.; Zhao, C.C.; Li, X.; Gao, Q.Z.; Huang, L.Q.; Xiao, P.G.; Gao, W.Y. The genus Polygonatum: A review of ethnopharmacology, phytochemistry and pharmacology. J. Ethnopharmacol. 2018, 214, 274-291. [CrossRef] [PubMed]

2. Liu, X.Q.; Yi, H.; Yao, L.; Ma, H.W.; Zhang, J.Y.; Wang, Z.M. Advances in plants of Polygonatum and discussion of its development prospects. Chin. Pharm. 2017, 52, 530-534.

3. Li, L.; Tian, L.N.; Ren, Z.X.; Long, Z.J. Research progress on the structural analysis and functional activity of polysaccharides. Chin. J. Exp. Tradit. Med. Fromul. 2015, 21, 231-234.

4. Zhang, H.X.; Cao, Y.Z.; Chen, L.X.; Wang, J.J.; Tian, Q.H.; Wang, N. A polysaccharide from Polygonatum sibiricum attenuates amyloid- $\beta$-induced neurotoxicity in PC12 cells. Carbohydr. Polym. 2015, 117, 879-886. [CrossRef] [PubMed]

5. Yelithao, K.; Surayot, U.; Lee, J.H.; You, S.G. RAW264.7 Cell Activating Glucomannans Extracted from Rhizome of Polygonatum sibiricum. Prev. Nutr. Food Sci. 2016, 21, 245-254. [CrossRef] [PubMed]

6. Zong, S.; Zeng, G.; Zou, B.; Li, K.K.; Fang, Y.; Lu, L.; Xiao, D.Q.; Zhang, Z.Y. Effects of Polygonatum sibiricum polysaccharide on the osteogenic differentiation of bone mesenchymal stem cells in mice. Int. J. Clin. Exp. Pathol. 2015, 8, 6169-6180. [PubMed]

7. Liu, N.; Dong, Z.H.; Zhu, X.S.; Xu, H.Y.; Zhao, Z.X. Characterization and protective effect of Polygonatum sibiricum polysaccharide against cyclophosphamide-induced immunosuppression in Balb/c mice. Int. J. Biol. Macromol. 2018, 107, 796-802. [CrossRef] [PubMed]

8. Zhao, X.Y.; Li, J. Chemical constituents of the genus Polygonatum and their role in medicinal treatment. Nat. Prod. Commun. 2015, 10, 683-688. [PubMed]

9. Shi, X.J.; Li, P.S.; Wei, Y.; Li, B.; Wang, D.C.; Xu, T.H.; Liu, T.H. Research progress on extraction and purification technologies and pharmacological effects of Polygonatum polysaccharide: A review. Guid. J. Tradit. Chin. Med. Pharm. 2015, 21, 103-105.

10. Peng, X.M.; He, J.C.; Zhao, J.M.; Wu, Y.L.; Shi, X.Z.; Du, L.; Nong, M.N.; Zong, S.H.; Zeng, G.F. Polygonatum sibiricum polysaccharide promotes osteoblastic differentiation through the ERK/GSK-3 $\beta$ / $\beta$-catenin signaling pathway in vitro. Rejuv. Res. 2017, 21, 44-52. [CrossRef] [PubMed]

11. Chopin, J.; Dellamonica, G.; Besson, E. C-galactosyl flavones from Polygonatum multiflorum. Phytochemistry 1977, 16, 1999-2001. [CrossRef]

12. Liu, L.; Dong, Q.; Dong, X.T.; Fang, J.N.; Ding, K. Structural investigation of two neutral polysaccharides isolated from rhizome of Polygonatum sibiricum. Carbohydr. Polym. 2007, 70, 304-309. [CrossRef]

13. Zhu, X.; Li, Q.; Lu, F.; Wang, H.; Yan, S.; Wang, Q.; Zhu, W. Antiatherosclerotic Potential of Rhizoma Polygonati Polysaccharide in Hyperlipidemia-induced Atherosclerotic Hamsters. Drug Res. 2015, 65, 479-483. [CrossRef] [PubMed]

14. Wang, S.Q.; Wang, B.; Hua, W.P.; Niu, J.F.; Dang, K.K.; Qiang, Y.; Wang, Z. De Novo Assembly and Analysis of Polygonatum sibiricum Transcriptome and Identification of Genes Involved in Polysaccharide Biosynthesis. Int. J. Mol. Sci. 2017, 18. [CrossRef] [PubMed]

15. Li, Y.; Deng, H.; Xiang, D. The effect of Polygonatic rhizome on hyperlipoidemia and anti-atherosclerosis. Chin. J. Arterioscler. 2005, 13, 429-431.

16. Yang, J.X.; Wu, S.; Huang, X.L.; Hu, X.Q.; Zhang, Y. Hypolipidemic Activity and Antiatherosclerotic Effect of Polysaccharide of Polygonatum sibiricum in Rabbit Model and Related Cellular Mechanisms. Evid. Based Complement. Altern. Med. 2015, 2015, 391065. [CrossRef] [PubMed] 
17. Chen, H.; Feng, S.S.; Sun, Y.J.; Hao, Z.Y.; Feng, W.S.; Zheng, X.K. Advances in studies on chemical constituents of three medicinal plants from Polygonatum Mill. And their pharmacological activities. Chin. Tradit. Herbal Drugs 2015, 46, 2329-2338.

18. Debnath, T.; Park, S.R.; Kim, D.H.; Jo, J.E.; Lim, B.O. Antioxidant and anti-inflammatory activity of Polygonatum sibiricum rhizome extracts. Asian Pac. J. Trop. Dis. 2013, 3, 308-313. [CrossRef]

19. Wang, H.; Yuan, P.D.; Zeng, C.H.; Chen, Z. The pharmacological action and clinical application of Polygonatum sibiricum. J. Hubei Inst. Natl. (Med. Sci.) 2017, 34, 58-64.

20. Ma, H.F.; Fang, H.L.; Liu, Z.Y. Study on the anti-fatigue effect of Polygonatum sibiricum polysaccharide. Mod. Soc. 2017, 9, 190.

21. Wu, L.H.; Lv, G.Y.; Li, B.; Zhang, Y.L.; Su, J.; Chen, S.H. Study on effect of Polygonatum sibiricum on Yin deficiency model rats induced by long-term overload swimming. Chin. J. Chin. Mater. Med. 2014, 39, 1886-1891.

22. Chen, G.; Chen, H.L.; Su, W.; Zhang, G.Z. Optimization of extraction technique of Polyonatic sibiricum polysaccharides by response surface analysis. Food Sci. 2007, 28, 198-201.

23. Zhu, Q.; Deng, X.; Zhang, S.B.; Mei, S.Y.; Chen, X.J.; Zhang, Y.F.; Li, Y.; Nie, Q.L.; Xiao, Q.M. Research progress in extraction technology, content determination and composition analysis of Polyonatum polysaccharides. Cent. South Pharm. 2017, 15, 1586-1590.

24. Zhao, R.M.; Sun, T.G.; Zhang, L. Extracting polysaccharides from Polygonatum with alkalineand optimizing of the extracting flow-sheet. Taishan Med. Coll. 2010, 31, 45-47.

25. Xu, B.B.; Yu, Y.J.; Wu, F.; Ni, S. Research progress of Polygonatum sibiricum polysaccharides. Chin. Wild Plant Resour. 2015, 34, 38-46.

26. Lu, J.P.; Zhang, J.; Zhang, Y.Z. The function activities and application of Polygonatum sibiricum polysaccharides. J. Food Saf. Qual. 2013, 4, 273-278.

27. Ni, W.P.; Zhu, X.X.; Wang, H.D.; Li, Q.Y.; Wan, M. Study on the protective mechanism of polysaccharide on the injury of human umbilical vein endothelial cells induced by lipopolysaccharide. Chin. Arch. Tradit. Chin. Med. 2012, 30, 2644-2648.

28. Wang, Y.Q.; Wu, X.L.; Zhang, G.X.; Cui, P.H.; Dai, L.M.; Yang, P. Experimental study on antioxidation of polysaccharide in rats. Chin. Mod. Doc. 2011, 49, 6-11.

29. Li, C.Y.; Zhou, Y.Y.; Xin, Q.F.; Zhang, Z.G. Effect of Polygonati polysaccharide on superoxide dismutase, malondialdehyde and blood lipoid metabolism in serum in twelve months natural climacteric rats. Chin. J. Gerontol. 2013, 33, 6215-6216.

30. Sheng, R.; Xu, X.; Tang, Q.; Bian, D.; Li, Y.; Qian, C.; He, X.; Gao, X.; Pan, R.; Wang, C.; et al. Polysaccharide of Radix pseudostellariae improves chronic fatigue syndrome induced by poly I:Cin mice. Evid. Based Complement. Altern. Med. 2011, 2011, 840516. [CrossRef] [PubMed]

31. Tan, W.; Yu, K.Q.; Liu, Y.Y.; Ouyang, M.Z.; Yan, M.H.; Luo, R.; Zhao, X.S. Anti-fatigue activityof polysaccharides extract from Radix Rehmanniae Preparata. Int. J. Biol. Macromol. 2012, 50, 59-62. [CrossRef] [PubMed]

32. Ni, W.; Gao, T.; Wang, H.; Du, H.; Li, Y.J.; Li, C.; Wei, L.; Bi, H. Anti-fatigue activity of polysaccharides from the fruits of four Tibetan plateau indigenous medicinal plants. J. Ethnopharmacol. 2013, 50, 529-535. [CrossRef] [PubMed]

33. Horng, C.T.; Huang, J.K.; Wang, H.Y.; Huang, C.C.; Chen, F.A. Antioxidant and antifatigue activities of Polygonatum Alte-lobatum Hayata rhizomes in rats. Nutrients 2014, 6, 5327-5337. [CrossRef] [PubMed]

34. Liu, S.Q. Effects of polysaccharides from Polygonatum on fatigue in mice. Chin. Mod. Med. 2009, 16, 31-32.

35. Linton, P.J.; Dorshkind, K. Age-related changes in lymphocyte development and function. Nat. Immunol. 2004, 5, 133-139. [CrossRef] [PubMed]

36. Weiskopf, D.; Weinberger, B.; Grubeck-Loebenstein, B. The aging of the immune system. Transpl. Int. 2009, 22, 1041-1050. [CrossRef] [PubMed]

37. Shen, J.; Liu, L.; Qian, J. Effects of Polygonatum polysaccharide on immunological activity of immunosuppressive mouse model. Drug Eval. Res. 2012, 35, 328-331.

38. Fu, S.; Qian, J.; Chen, L.; Liu, P. Extracting of Polygonatum polysaccharides and effecting on the immunological activity. J. Chin. Inst. Food Sci. Technol. 2013, 13, 68-72.

39. Li, Z.T.; Sun, J.X.; Zhu, H.X.; Chu, Z.F. Extracting of Polygonatum polysaccharides and its antimicrobial activity. Food Res. Dev. 2017, 38, 36-38. 
40. Zheng, C.Y.; Wang, H.F.; Zhang, T.T. Studies on the Anti-Micromial and Anti-Inflammatory Activities of Polygonatum Cyrtonema Hua. Polysaccharides. J. Anhui Norm Univ. (Nat. Sci.) 2010, 33, 272-275.

41. Cao, G.H.; Li, Z.D.; Zhao, R.H.; Zhang, Q.R.; Li, J.B.; He, Z.W.; Kang, K.; He, S. Compare of antibacterial effect produced by polysaccharides between raw materials and processing Polygonatum sibirium. Food Sci. Technol. 2017, 42, 202-206.

42. Crews, L.; Masliah, E. Molecular mechanisms of neurodegeneration in Alzheimer's disease. Hum. Mol. Genet. 2010, 19, 12-20. [CrossRef] [PubMed]

43. Maccioni, R.B.; Muñoz, J.P.; Barbeito, L. The molecular bases of Alzheimer's disease and other neurodegenerative disorders. Arch. Med. Res. 2001, 32, 367-381. [CrossRef]

44. Butterfield, D.A.; Drake, J.; Pocernich, C.; Castegna, A. Evidence of oxidative damage in Alzheimer's disease brain: Central role for amyloid beta-peptide. Trends Mol. Med. 2001, 7, 548-554. [CrossRef]

45. Zhang, F.; Zhang, J.G.; Wang, L.H.; Mao, D.X. Effects of Polygonatum sibiricum polysaccharide on learning and memory in a scopolamine-induced mouse model of dementia. Neural Regen. Res. 2008, 3, 33-36.

46. Wang, J.X. Experimental study of blood glucose and lipid-lowering effects of Polygona-polysacchrose. Chin. Med. Mod. Dist. Educ. Chin. 2009, 7, 93-94.

47. Xu, M.H.; Li, W.P.; Gong, H.L. Effects of Polygona-polysaccharose on blood glucose and lipid level of diabetic mice induced by alloxan. Anhui Med. Pharm. J. 2013, 13, 263-265.

48. Gong, H.L.; Li, W.P.; Yin, Y.Y. Hypoglycemic activity and mechanism of Polygona-polysaccharose on diabetic rat model. China J. Chin. Mater Med. 2009, 34, 1149-1154.

49. Gong, H.L. Study on the protective effect of polysaccharide on experimental diabetic animals and its mechanism. Anhui Med. Univ. 2009.

50. Wang, Y.; Qin, S.; Pen, G.; Chen, D.; Han, C.; Mao, C.; Lu, B.; Su, C.; Feng, S.; Li, W.; et al. Original Research: Potential ocular protection and dynamic observation of Polygonatum sibiricum polysaccharide against streptozocin-induced diabetic rats' model. Exp. Biol. Med. 2017, 242, 92-101. [CrossRef] [PubMed]

51. Yan, H.; Lu, J.; Wang, Y.; Gu, W.; Yang, X.G.; Jie, Y. Intake of total saponins and polysaccharides from Polygonatum kingianum affects the gut microbiota in diabetic rats. Phytomedicine 2017, 26, 45-54. [CrossRef] [PubMed]

52. Zhao, H.L.; Xu, Y.; Zhao, H.Y.; Liu, Y.; Zhao, W.M. Effect of polysaccharide on the expression of SREBP-1 and SCD-1in rats with type2 diabetes mellitus. Chin. Med. Pharm. Clin. 2015, 31, 106-109.

53. Zhang, Z.Y.; Wang, G.X.; Chen, T.T.; Fu, T.T. Effect of polysaccharide on myocaridal of diabetic rats. Chin. J. Public Health 2016, 32, 807-810.

54. Chen, T.T.; Wang, G.X.; Fu, T.T.; Zhang, Z.Y. The protective effect of Polygonatum sibiricum polysaccharede on myocardial inflammation in type I diabetic rats. Chin. Med. Pharm. Clin. 2015, 31, 86-90.

55. Fu, T.T.; Wang, G.X.; Chen, T.T.; Zhang, Z.Y. The protective effect of Polygonatum sibirium polyszccharide on diabetic nephropathy rats. Chin. Med. Pharm. Clin. 2015, 31, 123-126.

56. Zeng, G.F.; Zhang, Z.Y.; Lu, L.; Xiao, D.Q.; Xiong, C.X.; Zhao, Y.X.; Zong, S.H. Protective effects of Polygonatum sibiricum polysaccharide on ovariectomy-induced bone loss in rats. J. Ethnopharmacol. 2011, 136, 224-229. [CrossRef] [PubMed]

57. Nong, M.N.; Zeng, G.F.; Zong, S.H. Polygonatum sibiricum polysaccharide regulates osteoblastic differentiation of mouse bone marrow-derived mesenchymal stem cells. Chin. J. Tissue Eng. Res. 2016, 20, 2133-2139.

58. Du, L.; Nong, M.N.; Zhao, J.M.; Peng, X.M.; Zong, S.H.; Zeng, G.F. Polygonatum sibiricum polysaccharide inhibits osteoporosis by promoting osteoblast formation and blocking osteoclastogenesis through Wnt/ $\beta$-catenin signalling pathway. Sci. Rep. 2016, 6, 32261. [CrossRef] [PubMed]

59. Nakamura, T.; Hanada, K.; Tamura, M.; Shibanushi, T.; Nigi, H.; Tagawa, M.; Fukumoto, S.; Matsumoto, T. Stimulation of endosteal bone formation by systemicinjections of recombinant basic fibroblast growth factor in rats. Endocrinology 1995, 136, 1276-1284. [CrossRef] [PubMed]

60. Han, S.Y.; Hu, M.H.; Qi, G.Y. Polysaccharides from Polygonatum Inhibit the Proliferation of Prostate Cancer-Associated Fibroblasts. Asian Pac. J. Cancer Prev. 2016, 17, 3829-3833. [PubMed]

61. Jiang, H. Study on anti-tumor activity of Polygonatum sibirium polysaccharide. J. Nanjing Univ. Chin. Med. 2010, 26, 479-480.

62. Wang, T.; Miao, M.S. Chemical pharmacology and clinical application of Polygonatum sibirium. J. Tradit. Chin. Med. 2015, 30, 714-718. 
63. He, C.T.; Li, W. Research progress on pharmacological efficacy of polysaccharide. J. New Chin. Med. 2014, 46, 196-199.

64. Wang, Y.; Alonso, A.P.; Wilkerson, C.G.; Keegstra, K. Deep EST profiling of developing fenugreek endosperm to investigate galactomannan biosynthesis and its regulation. Plant Mol. Biol. 2012, 79, 243-258. [CrossRef] [PubMed]

65. Pauly, M.; Gille, S.; Liu, L.; Mansoori, N.; Souza, A.D.; Schultink, A.; Xiong, G. Hemicellulose biosynthesis. Planta 2013, 238, 627-642. [CrossRef] [PubMed]

66. Xie, Y.; Zhou, H.; Liu, C.; Zhang, J.; Li, N.; Zhao, Z.; Sun, G.; Zhong, Y. A molasses habitat-derived fungus Aspergillus tubingensis XG21 with high $\beta$-fructofuranosidase activity and its potential use for fructooligosaccharides production. AMB Express 2017, 7, 1-9. [CrossRef] [PubMed]

67. Uematsu, K.; Suzuki, N.; Iwamae, T.; Inui, M.; Yukawa, H. Expression of Arabidopsis plastidial phosphoglucomutase in tobacco stimulates photosynthetic carbon flow into starch synthesis. J. Plant Physiol. 2012, 169, 1454-1462. [CrossRef] [PubMed]

68. Zhang, Y.; Zhen, L.; Tan, X.; Li, L.; Wang, X. The involvement of hexokinase in the coordinated regulation of glucose and gibberellin on cell wall invertase and sucrose synthesis in grape berry. Mol. Biol. Rep. 2014, 41, 7899-7910. [CrossRef] [PubMed]

69. Perez-Cenci, M.; Salerno, G.L. Functional characterization of Synechococcus amylosucrase and fructokinase encoding genes discovers two novel actors on the stage of cyanobacterial sucrose metabolism. Plant Sci. 2014, 224, 95-102. [CrossRef] [PubMed]

70. Park, J.I.; Ishimizu, T.; Suwabe, K.; Sudo, K.; Masuko, H.; Hakozaki, H.; Nou, I.S.; Suzuki, G.; Watanabe, M. UDP-glucose pyrophosphorylase is rate limiting in vegetative and reproductive phases in Arabidopsis thaliana. Plant Cell Physiol. 2010, 51, 981-996. [CrossRef] [PubMed]

71. Bachmann, P.; Zetsche, K. A close temporal and spatial correlation between cell growth, cell wall synthesis and the activity of enzymes of mannan synthesis in Acetabularia mediterranea. Planta 1979, 145, 331-337. [CrossRef] [PubMed]

72. Yin, Y.; Huang, J.; Gu, X.; Bar-Peled, M.; Xu, Y. Evolution of plant nucleotide-sugar interconversion enzymes. PLoS ONE 2011, 6, e27995. [CrossRef] [PubMed] 